\title{
Five Tips for Becoming an Ideal General Hospitalist
}

\author{
Masaki Tago (D) \\ Takashi Watari ${ }^{2}$ \\ Kiyoshi Shikino (I) $^{3}$ \\ Yosuke Sasaki $\mathbb{1}^{4}$ \\ Hiromizu Takahashi ${ }^{5}$ \\ Taro Shimizu ${ }^{6}$
}

'Department of General Medicine, Saga University Hospital, Saga, Japan; ${ }^{2}$ General Medicine Center, Shimane University Hospital, Shimane, Japan; ${ }^{3}$ Department of General Medicine, Chiba University Hospital, Chiba, Japan; ${ }^{4}$ Department of General Medicine and Emergency Care, Toho University School of Medicine, Tokyo, Japan; ${ }^{5}$ Department of General Medicine, Faculty of Medicine, Juntendo University, Tokyo, Japan; ${ }^{6}$ Department of Diagnostic and Generalist Medicine, Dokkyo Medical University, Tochigi, Japan

Correspondence: Masaki Tago Department of General Medicine, Saga University Hospital, 5-I-I Nabeshima,

Saga, 849-850I, Japan

Tel +81 952343238

Fax +8I 952342029

Email tagomas@cc.saga-u.ac.jp

\begin{abstract}
Owing to the social structure issues caused by Japan's super-aged society, healthcare roles have become more complex, and the need for general physicians has increased. General hospitalists in Japan perform various roles. Thus, the ideal image of general hospitalists there has been unclear. We summarize the 10 key skills for Japanese hospitalists indicated in the specialty programs of the Japanese Society of Hospital General Medicine. We identified the following five crucial points for ideal general hospitalists: general mindset; leadership and management; community-based comprehensive care and cooperation with various professions; appropriate medical interviewing, physical examination, and diagnostic reasoning; and proactive education and academic activities. This paper presents five tips, which deal with why those items are necessary and how they should be learned.
\end{abstract}

Keywords: academic activity, diagnostic reasoning, education, general hospitalist, general mindset, leadership and management

Japan is regarded as a super-aged society, with the highest rate of aging in the world ${ }^{1}$ that has led to an increasing number of multimorbidity patients with complex problems. ${ }^{2}$ Furthermore, social structure issues, such as rural depopulation, have added to the difficulties concerning the crucial role of health care. ${ }^{3}$ In Japan, medical specialties were originally subdivided in terms of organs; thus, it has become challenging to perform community medicine using only specialized medical treatment by organ-specific specialists. Therefore, according to the new medical specialty system introduced in 2019, general medicine (GM) became established as the 19th basic specialty field. ${ }^{4}$ In addition, the Japanese Society of Hospital General Medicine (JSHGM) is planning to start a hospitalist specialty program in $2022 .^{5}$ The new Japanese hospitalist specialty program was developed based on the Core Competencies in Hospital Medicine by the Society of Hospital Medicine. ${ }^{6}$ Accordingly, the standards related to general hospitalists in Japan and the United States should be similar. Thus, the momentum for GM is growing in Japan.

Japanese generalists have to play various roles depending on their work setting, such as attributes and regional characteristics; general hospitalists are also naturally expected to be diverse. ${ }^{7}$ However, that diversity has obscured the definition of generalists in Japan; the role of generalists has yet to be clarified. ${ }^{8}$ Accordingly, as specialist program committee members of the JSHGM, we have proposed 10 key skills for Japanese general hospitalists $^{9}$ in the program. ${ }^{5}$ The present article summarizes the 10 skills and presents five tips (Table 1), which deal with why those items are necessary and how they should be learned. The tips were developed following discussion among the six members of the specialist program committee of the JSHGM (who developed the 10 skills) and three Japanese general hospitalists working in community hospitals as well as a narrative review by those six committee members. 
Table I Five Tips for Becoming an Ideal General Hospitalist

Tip I. General mindset

Attitude when dealing with any patients, symptoms, and complaints and trying to find better solutions

Tip 2. Leadership and management

Negotiations, analyzing hospital operations, and assessing the quality of medical care to improve patient outcomes, resource use, costeffectiveness, and quality of medical care for hospitalized patients

Tip 3. Community-based comprehensive care and cooperation with various professions

Developing a system to provide comprehensive support for medical care, long-term care, preventive care, housing, and support for daily

living in the community based on trustworthy cooperation with various professions

Tip 4. Appropriate medical interviewing, physical examination, and diagnostic reasoning

Identifying the patient's primary problem with proper diagnostic reasoning using a well-conducted medical interview and physical examination; making a correct diagnosis and treatment

Tip 5. Proactive education and academic activities Developing the academic field of general medicine through the proactive education of generalists by general hospitalists themselves and engaging in academic activities

\section{Tip I. General Mindset}

"General mindset" signifies the spirit of a physician who is always available to provide consultation and find better solutions for any patient, symptom, or complaint under any situation without refusing. ${ }^{10}$

\section{Why Does a General Hospitalist Need a General Mindset?}

The general mindset is a fundamental part of GM. In Japan's complex, highly fragmented medical system, a general mindset is essential to provide appropriate medical care for patients. Moreover, because GM is a social need, as evident in Japan's medical specialty system, ${ }^{4}$ Japanese generalists should fulfill it.

\section{How Does a General Hospitalist Acquire a General Mindset?}

It is necessary for general hospitalists to find an appropriate role model and request mentoring. ${ }^{11}$ Alternatively, a general mindset can be acquired from colleagues who apply such a mindset in their work. It is important to adopt the attitude of coping with everything and then applying a strong mentality. However, coping by oneself does not mean that generalists should undertake all work themselves. A key skill of generalists is the ability to consult and receive assistance from specialists in other fields. ${ }^{12}$ The interface between generalists and specialists is also an important fulcrum in medical decisionmaking. ${ }^{12}$

\section{Tip 2. Leadership and Management}

The JSHGM specialty program includes hospital administration and social skills, ${ }^{5}$ and those skills are based on leadership and management.

Why Does a General Hospitalist Need Leadership and Management Skills?

General hospitalists need to have leadership roles in the community, hospital, and clinical team; they should lead efforts to identify, assess, and improve patient outcomes, resource use, cost-effectiveness, and quality of hospital care. ${ }^{13}$ To improve their hospitals, general hospitalists are expected to manage negotiations, business analysis, and quality measurement. According to Kotter's framework, both management and leadership are required concurrently, and the differences in the roles and taskachieving process of each are clearly defined. ${ }^{14}$ For example, regarding the function of deciding what needs to be done, the managerial role would involve planning and budgeting while the leadership role would involve setting direction.

How Does a General Hospitalist Acquire Leadership and Management Skills?

General hospitalists are always expected to undertake leadership and management in varying degrees in the medical team, cross-disciplinary team, department, hospital, and elsewhere. ${ }^{15}$ General hospitalists can learn much from practice and failure. However, it is possible to acquire and master leadership and management skills. Obtaining hints from the literature and learning from leadership management training courses conducted by the Society of Hospital Medicine are effective methods of learning. ${ }^{16}$

\section{Tip 3. Community-Based Comprehensive Care and Cooperation with Various Professions}

To cope with its aged society, Japan aims to establish a comprehensive system of medical care, long-term care, preventive care, housing, and support for daily life so that people requiring long-term care can live independently in 
their communities for as long as possible. ${ }^{17}$ With that system, general hospitalists should cooperate not only in hospitals but also with various professions in the community. Other countries have introduced comprehensive systems to cope with the aging of their societies and have tested the effectiveness. ${ }^{18}$

Why Does a General Hospitalist Need to Contribute to Community-Based Comprehensive Care and Cooperate with Various Professions?

Japanese society needs community-based comprehensive care. Treating the patient's entire life is a fundamental concept of GM. Furthermore, health care cannot be performed only in hospitals. Thus, general hospitalists need to be proactive in patients' lives following discharge. However, community-based comprehensive care cannot be provided only by physicians. Therefore, general hospitalists need to cooperate with various professions to provide the best medical and long-term care with respect to patients' values, lifestyles, economy, and social backgrounds.

\section{How Does a General Hospitalist Learn Community-Based Comprehensive Care and} Cooperation with Various Professions?

As well as in hospitals, general hospitalists should gain experience in other settings, such as local clinics, remote areas, nursing facilities, community hospitals, and advanced acutecare hospitals. Thus, it is insufficient if general hospitalists have only an imbalanced experience in clinics or hospitals.

\section{Tip 4. Appropriate Medical Interviewing, Physical Examination, and Diagnostic Reasoning}

Medical interviewing, physical examination, and diagnostic reasoning are essential skills for all physicians. However, in a highly fragmented medical system, examination-based medicine and medical care without the patient being present are sometimes practiced; in such cases, the medical history and physical examination can be disregarded. ${ }^{19}$

\section{Why Does a General Hospitalist Need to Practice Appropriate Medical Interviewing, Physical Examination, and Diagnostic Reasoning?}

Appropriate diagnostic reasoning based on a detailed medical history and physical findings is one of the specialties of GM. Therefore, general hospitalists should identify the patient's primary problem and make a correct diagnosis and treatment. Considering Japan's recent financial problems, requiring substantial social security expenses every year, ${ }^{20}$ it would be beneficial to reduce costs by selecting appropriate examinations and treatments.

How Does a General Hospitalist Learn Appropriate Medical Interviewing, Physical Examination, and Diagnostic Reasoning?

They are basic medical skills that physicians should acquire from books and practice. In light of the importance of these skills, it is necessary always to perform careful medical interviews, physical examinations, and diagnostic reasoning without omissions. ${ }^{21}$

\section{Tip 5. Proactive Education and Academic Activities}

Because GM is based on medical professionalism and basic clinical skills, it has an extremely high affinity with medical education. ${ }^{22}$ Moreover, academic development in the specialty cannot be expected without undertaking academic activities; however, this point is not limited to GM.

Why Does a General Hospitalist Need Proactive Education and Academic Activities?

Only generalists can be responsible for educating generalists. To develop high-quality general hospitalists, it is necessary for general hospitalists themselves to proactively educate medical students, residents, fellows, and colleagues. In addition, the academic activities of general hospitalists must reinforce the specialties of GM. Finally, general hospitalists should recognize that they are responsible for accumulating knowledge through research (including case reports based on clinical practice) and developing their field as an academic science.

How Does a General Hospitalist Undertake Education and Academic Activities?

It is necessary to master the educational framework of best evidence medical education through training programs and postgraduate courses. ${ }^{23}$ General hospitalists can also join academic groups and practice education in real settings. Regarding academic activities, it is crucial for general hospitalists to understand the necessity of such activities with an inquisitive spirit and broad perspective; they need to keep their motivation high, establish good relationships with mentors and colleagues, create an effective research environment, recognize that research and academic writing are skills that can be mastered, and begin boldly with ambition. ${ }^{24,25}$

These five tips are the opinions of six expert general hospitalists: other tips may be more appropriate for general hospitalists. To clarify this point would require a survey 
targeting intermediate-level or higher general hospitalists to quantify their skills. Nevertheless, we hope that these five tips will help in the training of young doctors and assist many general hospitalists.

\section{Abbreviations}

GM, general medicine; JSHGM, Japanese Society of Hospital General Medicine.

\section{Acknowledgments}

We thank Dr. Makoto Oura, Dr. Ken Goda, and Dr. Mai Hongo for their kind support for this work. We also thank Edanz for editing a draft of this manuscript.

\section{Author Contributions}

All the authors made a significant contribution to the work reported with respect to the conception, study design, execution, acquisition of data, analysis, and interpretation. All authors took part in drafting, revising, or critically reviewing the article, and they gave their final approval of the version submitted for publication. All the authors have agreed on the journal for submission and agree to be accountable for all aspects of the work.

\section{Funding}

There is no funding to report.

\section{Disclosure}

Masaki Tago is supported by grants from the Japan Society for the Promotion of Science, JSPS KAKENHI Grant Number JP18K17322 and JP21H03166. The sponsor of the study had no role in the preparation of the manuscript. The authors report no other conflicts of interest in this work.

\section{References}

1. Cabinet Office. Government of Japan: Annual report on the ageing society [Web site]. Available from: https://www8.cao.go.jp/kourei/ whitepaper/w-2020/html/zenbun/s1_1_2.html. Accessed September 17, 2021. (in Japanese).

2. Puth MT, Weckbecker K, Schmid M, Münster E. Prevalence of multimorbidity in Germany: impact of age and educational level in a cross-sectional study on 19,294 adults. BMC Public Health. 2017;17 (1):826. doi:10.1186/s12889-017-4833-3

3. Taniguchi S, Park D, Inoue K, Hamada T. Education for community-based family medicine: a social need in the real world. Yonago Acta Med. 2017;60(2):77-85. doi:10.33160/yam.2017.06.002

4. Japanese Medical Specialty Board. Specialist of general medicine [Web site]. Available from: https://jmsb.or.jp/sogo\#an02. Accessed September 17, 2021. (in Japanese).
5. Japanese society of hospital general medicine [Web site]. Available from: http://hgm-japan.com/system/process04/. Accessed September 17, 2021. (in Japanese).

6. Nichani S, Fitterman N, Lukela M, Crocker J. The core competencies in hospital medicine 2017 revision. J Hosp Med. 2017;12(4 Supp1 1):283-287. doi:10.12788/jhm.2715

7. Wachter RM. An introduction to the hospitalist model. Ann Intern Med. 1999;130(4_Part_2):338-342. doi:10.7326/0003-4819-1304-199902161-00002

8. Watari T. The new era of academic hospitalist in Japan. J Gen Fam Med. 2020;21(2):29-30. doi:10.1002/jgf2.299

9. Tago M, Watari T, Shikino K, Sasaki Y, Takahashi H, Shimizu T. A statement on the ten fascinating skills of the Japanese hospitalist. J Hosp Gen Med. 2021;3:68-70.

10. Quill TE, Cassel CK. Nonabandonment: a central obligation for physicians. Ann Intern Med. 1995;122(5):368-374. doi:10.7326/ 0003-4819-122-5-199503010-00008

11. Said M, Jochemsen-van der Leeuw RHGA, Spek B, Brand PLP, van Dijk N. Role modelling in the training of hospital-based medical specialists: a validation study of the Role Model Apperception Tool (RoMAT). Perspect Med Educ. 2019;8(4):237-245. doi:10.1007/ s40037-019-00527-6

12. Pearson SD. Principles of generalist-specialist relationships. $J$ Gen Intern Med. 1999;14(Suppl 1):S13-S20. doi:10.1046/j.1525-1497.1999.00259.x

13. Yousefi V, McIvor E. Characteristics of the ideal hospitalist inpatient care program: perceptions of Canadian health system leaders. $B M C$ Health Serv Res. 2021;21(1):648. doi:10.1186/s12913-021-06700-0

14. Wheeler TR, Holmes KL. Rapid transformation of two libraries using Kotter's eight steps of change. J Med Libr Assoc. 2017;105 (3):276-281. doi:10.5195/JMLA.2017.97

15. Tummalapalli SL. Leadership and professional development: cultivating habits for the hospitalist. J Hosp Med. 2020;15(3):169. doi: $10.12788 / \mathrm{hm} .3276$

16. SHM's Leadership Academy. Society of hospital medicine [Web site]. Available from: https://www.hospitalmedicine.org/event/leader ship-academy/. Accessed September 17, 2021.

17. Tsukada Y, Kodani E, Asai K, Yasutake M, Seino Y, Shimizu W. Status of medical care and management requirements of elderly patients with heart failure in a comprehensive community health system - Survey of general practitioners' views. Circ Rep. 2021;3 (2):77-85. doi:10.1253/circrep.CR-20-0132

18. Brown L, Forster A, Young J, Crocker T, Benham A, Langhorne P. Medical day hospital care for older people versus alternative forms of care. Cochrane Database Syst Rev. 2015;2015(6):CD001730.

19. Fred HL. Hyposkillia: deficiency of clinical skills. Tex Heart Inst J. 2005;32(3):255-257.

20. Public relations office of the government of Japan [Web site]. Available from: https://www.gov-online.go.jp/tokusyu/syaho/naze/hit suyosei.html. Accessed September 17, 2021. (in Japanese.)

21. Shimizu T. The 6C model for accurately capturing the patient's medical history. Diagnosis. 2021. doi:10.1515/dx-2020-0126

22. Dalen JE, Ryan KJ, Waterbrook AL, Alpert JS. Hospitalists, medical education, and U.S. health care costs. Am J Med. 2018;131 (11):1267-1269. doi:10.1016/j.amjmed.2018.05.016

23. Harden RM, Grant J, Buckley G, Hart IR. BEME Guide No. 1: Best evidence medical education. Med Teach. 1999;21(6):553-562. doi: $10.1080 / 01421599978960$

24. Shikino K, Watari T, Tago M, Sasaki Y, Takahashi H, Simizu T. Five tips on writing case reports for Japanese generalists. J Gen Fam Med. 2021;22(2):111-112. doi:10.1002/jgf2.395

25. Tago M, Watari T, Shikino K, Sasaki Y, Takahashi H, Shimizu T. Five tips on clinical research for young Japanese generalists. $J$ Hosp Gen Med. 2021;3:108-110. 


\section{Publish your work in this journal}

The International Journal of General Medicine is an international, peer-reviewed open-access journal that focuses on general and internal medicine, pathogenesis, epidemiology, diagnosis, monitoring and treatment protocols. The journal is characterized by the rapid reporting of reviews, original research and clinical studies across all disease areas. The manuscript management system is completely online and includes a very quick and fair peer-review system, which is all easy to use. Visit http://www.dovepress.com/ testimonials.php to read real quotes from published authors.

Submit your manuscript here: https://www.dovepress.com/international-journal-of-general-medicine-journal 